\title{
Laypersons' knowledge about the sequelae of minor head injury and whiplash
}

\author{
JOCELYN B AUBREY, ALLEN R DOBBS, BRENDAN GAIL RULE \\ From the Department of Psychology, University of Alberta, Edmonton, Alberta, Canada
}

SUMMARY Even minor head injuries can result in the post traumatic syndrome, a symptom complex that includes physical discomfort and sleep, sexual, affective, and memory disturbance. Little is known about the layperson's knowledge of the syndrome but this may influence judgements about malingering and attitudes towards victims of minor head injury. Descriptions of rear-end automobile accidents were presented to two groups. One group $(n=22)$ rated the likelihood of a variety of physical, affective, cognitive, and distractor (never or rarely reported by trauma victims) symptoms. A second group $(n=21)$ judged the speed necessary to cause each of the symptoms. The results indicated that highly exaggerated speeds were thought necessary to produce even the most common physical symptoms. Moreover, cognitive symptoms were thought to be no more likely than were distractor symptoms. In.contrast, the knowledge about physical symptoms, the effects of loss of consciousness and whiplash versus direct head injuries was consistent with what is known from research literature.

It is well recognised that even a mild head injury resulting in only momentary loss of consciousness (LOC) can be followed by symptoms that include physical, affective and memory problems. The term "post traumatic syndrome" (PTS) is commonly used to describe this constellation of persisting symptoms. There is, however, disagreement over the likelihood that symptoms persisting beyond a few weeks or months are directly attributable to the head injury (see Binder, 1986 for a comprehensive review'). The continuation of complaints that do not appear to have an identifiable physiological basis (such as abnormal CT scan, EEG) has been ascribed to neurotic anxiety, exaggeration or malingering. ${ }^{2-4}$

An accurate simulation of the PTS clearly requires that the person know the complex of symptoms to express. The possibility that the PTS symptomatology is commonly known, is of primary interest in this research. A documentation of the extent of common knowledge about the sequelae of whiplash and minor head injury is important for two reasons. First, such knowledge can be helpful for judgements about malingering. If, for example, the common knowledge differs

Address for reprint requests: $\operatorname{Dr}$ A $\mathbf{R}$ Dobbs, Department of Psychology, University of Alberta, Edmonton, Alberta, Canada T6G 2E9.

Received 14 June 1988 and in revised form 12 December 1988. Accepted 24 January 1989 in some respect from the actual symptomatology, then $\overrightarrow{0}-\vec{C}$ that information might be useful in identifying fabrications. Second, and perhaps more importantly, the common knowledge about the sequalae of these injuries can be of considerable utility in understanding attitudes of family, friends, juries and others to persons who are in no way malingering, but for whom the symptom complex has a real physical basis.

\section{Method}

\section{Subjects and procedure}

Forty three university students participated as an option for an Introductory Psychology course requirement. Minor head injury was not a topic covered in the course and they were unaware of the goals of the research at the time they volunteered to participate. Twenty two subjects completed a likelihood judgement task and 21 subjects made speed judgements. Both groups read one short description of a car accident and made judgements about 50 symptoms and five outcomes that might have been experienced by the driver. Each group then read a second, different accident description and made judgements about the symptoms and outcomes for that situation. The two descriptions were given to about half of each group in one order ( $A$ followed by $B$ ) and presented in the other order (B followed by A) to the remaining subjects. Two random presentation orders of the symptom and outcome list were used.

The symptom list included items from five categories: Physical symptoms (HiPhys) frequently reported in the literature as typical of the PTS, less frequently reported but none the less representative physical symptoms (LoPhys), 
affective symptoms (Affect), cognitive impairment symptoms (Cognitive), and distractor symptoms that never (or rarely) are reported to be related to the syndrome (Distractor). The HiPhys symptoms included headache, neck pain, ringing in the ears, and dizziness. LoPhys symptoms included injury to back muscles, low back pain, and occasional blackouts. Affective items included depression, lack of emotional control, anxiety, and irritability. Cognitive items included difficulty remembering phone numbers or names, difficulty concentrating, and other memory problems. The Distractor set included items such as heart trouble and occasional bouts of uncontrollable laughter. The list also included the following five outcome items; difficulty with social relationships, financial difficulties, poor performance at work, loss of interest in sex, and brain damage.

In the Likelihood Judgement condition, the accident descriptions differed in terms of whether or not LOC (loss of consciousness) occurred. The No LOC description was: "The driver of an average-sized North American car was stopped at an intersection waiting for the traffic light to change when the car was struck from behind by another car of the same make. The driver's head did not strike anything although the force of the impact did cause the head to jerk backwards resulting in a whiplash injury. The driver did not lose consciousness." The LOC description was the same except for the last sentence which stated that "the driver lost consciousness for ten minutes". For each of the symptoms and outcomes, particpants indicated whether that symptom would occur.

In the Speed Rating condition, rear-end accident conditions were described that differed in terms of the type of injury but LOC was not specified. In one description, the accident resulted in a whiplash injury. In the other descripton, the driver's head hit the windshield. Participants estimated how fast they thought the offending vehicle would have had to be moving in order to cause each symptom. Ratings were made using a seven point scale with 0 representing $1 \mathrm{~km} / \mathrm{h}$ and 6 representing $75 \mathrm{~km} / \mathrm{h}$.

\section{Results}

\section{Likelihood judgements}

The percent of items within each category endorsed as a likely consequence of the accident was calculated for each subject. The data were analysed in a $2 \times 5(\mathrm{LOC} /$ No LOC $\times$ Item Category) repeated measures analysis of variance. The symptoms were judged to be likely by more people when the accident victim was described as having lost consciousness than when no loss of consciousness occurred (LOC $M=67 \%$, No LOC $M=57 \%), F(1,21)=21.83, p<0.001$. A reliable effect was found for item category $F(4$, $84)=41.61, p<0.001$, indicating that the subjects judged symptoms from the various categories to be differentially likely. The Newman-Keuls test of the category mean ratings showed that the HiPhys symptoms were judged to be likely by more people $(M=88 \%)$ than were symptoms from any other category. The mean ratings for the LoPhys $(68 \%)$ and
Affective (74\%) categories were not reliably different, but those percentages were higher than those obtained for either the Cognitive or Distractor items. Statistically, the Cognitive symptoms (43\%) were judged to be no more likely than were Distractor symptoms $(37 \%)$ that have little or no relationship to the PTS. The likelihood judgements are presented on the left side of the fig in terms of the mean percent of subjects rating the items from each symptom category as being a likely consequence of the accident when LOC did and did not occur.

Part A of the table shows likelihood judgements for the outcome items. These were analysed in a $2 \times 5$ (LOC/No LOC $\times$ Outcome) repeated measures analysis of variance. All outcomes were judged to be more likely if $L O C$ resulted from the accident than if it did not, $F(1,21)=5.47, p<0.03$. The NewmanKeuls procedure indicated that this difference was significant $(p<0.05)$ only for the outcome "brain damage". The main effect of Outcome was statistically reliable, $F(4,84)=5.81, p<0.001$. The NewmanKeuls test indicated that the individual means do not differ but the level of responding is instructive. Half or fewer of the people believed that there might be social, financial, or sexual problems. It is important to note that these judgements were not about whether there would be long standing difficulties. They were judgements simply about whether that type of difficulty might be experienced.

\section{Speed judgements}

The mean speeds judged necessary to produce the symptoms in each category for whiplash and minor head injury were calculated and are presented in the right-hand portion of the fig. These data were analysed in a $2 \times 5$ (Injury Type $\times$ Item Category) repeated measures analysis of variance. The difference between the speed ratings $F((1,20)=10.93, p<0.01$ showed that more extreme speeds (in $\mathrm{km} / \mathrm{h}$ ) were judged to cause symptoms when the accident resulted in a whiplash injury $(M=46.4)$ rather than a direct blow to the head $(M=41 \cdot 6)$. The main effect of the speeds estimated as necessary to produce symptoms from the five categories was reliable, $F(4,80)=15.98$, $p<0.001$. The Newman-Keuls test indicated that reliably higher speeds were rated as necessary to cause the Cognitive $(M=50 \cdot 1)$ and Distractor $(M=48 \cdot 0)$ symptoms rather than the HiPhys symptoms $(M=37.0)$. The speed estimates for LoPhys and Affect symptoms were similar to all other categories ( $M s=44.0$ and 40.9, respectively).

Part B of the table shows the speeds judged to be necessary to cause the outcomes. It will be recalled that few people from the other group judged these outcomes to be likely. The generality of this belief is reflected in the very high speed ratings given by this 

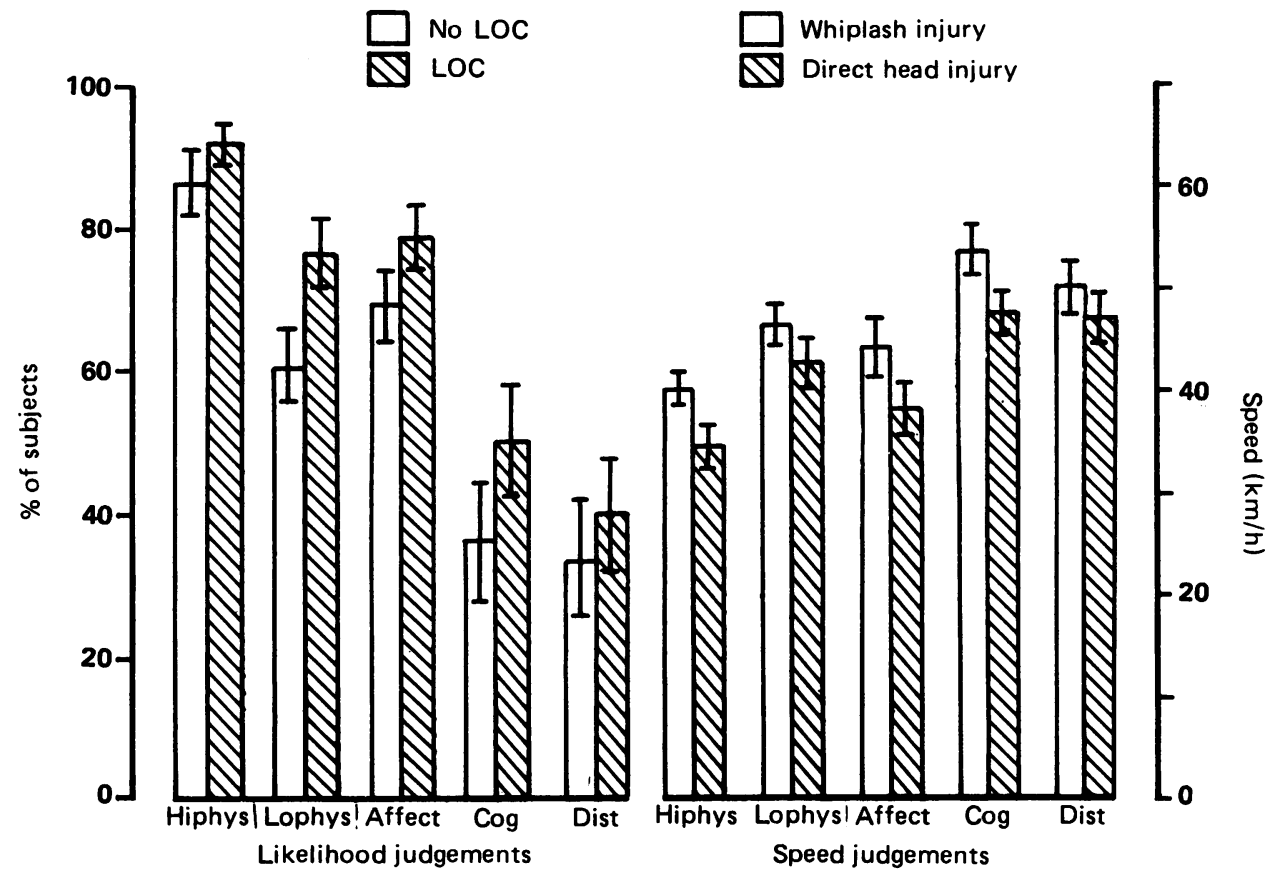

Fig Left: Mean percentage of subjects who judged each symptom category as likely to occur when the accident involved LOC or No LOC. Right: Mean speed judged necessary to cause each symptom category when the accident resulted in whiplash or direct head injury. Vertical bars represent standard errors.

second group. The loss of consciousness item was included to assess beliefs about speeds necessary to produce loss of consciousness with whiplash and head injury. A $2 \times 6$ (Type of Injury $\times$ Outcome) repeated measures analysis of variance was computed. More extreme speeds were judged to be required to cause the outcome when the accident resulted in a whiplash injury rather than a direct head injury, $F(1$, 20) $=14.25, p<0.002$. The main effect of the speeds necessary to produce the different outcomes was reliable, $F(5,100)=1.75, p<0.001$. The Newman-
Keuls test indicated that higher speeds were judged to be required to produce brain damage and problems with sex than were judged necessary to cause financial and work problems. The speed estimates for LOC and social relationship difficulties did not differ significantly from those judged for the other outcomes.

Correlations between Likelihood Judgements and Speed Ratings

The group scores for the individual items were rank ordered from highest to lowest (percentages of

Table Likelihood Judgements and Speed Ratings for the Outcome Items

\begin{tabular}{|c|c|c|c|c|c|c|}
\hline & $\begin{array}{l}\text { Work } \\
\text { Problems }\end{array}$ & $\begin{array}{l}\text { Social } \\
\text { Problems }\end{array}$ & $\begin{array}{l}\text { Brain } \\
\text { Damage }\end{array}$ & $\begin{array}{l}\text { Finance } \\
\text { Problems }\end{array}$ & $\begin{array}{l}\text { Sex } \\
\text { Problems }\end{array}$ & $\begin{array}{l}\text { Overall } \\
\text { Mean }\end{array}$ \\
\hline $\begin{array}{l}\text { No LOC } \\
\text { LOC } \\
\text { Overall Mean }\end{array}$ & $\begin{array}{l}68(11) \\
78(9) \\
73.0\end{array}$ & $\begin{array}{l}50(11) \\
41(11) \\
45 \cdot 5\end{array}$ & $\begin{array}{l}41(11) \\
68(10) \\
54 \cdot 5\end{array}$ & $\begin{array}{l}32(10) \\
36(11) \\
34 \cdot 0\end{array}$ & $\begin{array}{l}32(10) \\
46(11) \\
39 \cdot 0\end{array}$ & $\begin{array}{l}44 \cdot 6 \\
53 \cdot 8 \\
49 \cdot 2\end{array}$ \\
\hline
\end{tabular}

(B) Mean Speeds (in $\mathrm{km} / \mathrm{h}$ ). Judged to be required for outcomes and standard errors in brackets

\begin{tabular}{|c|c|c|c|c|c|c|c|}
\hline & $\begin{array}{l}\text { Work } \\
\text { Problems }\end{array}$ & $\begin{array}{l}\text { Social } \\
\text { Problems }\end{array}$ & $\begin{array}{l}\text { Brain } \\
\text { Damage }\end{array}$ & $\begin{array}{l}\text { Finance } \\
\text { Problems }\end{array}$ & $\begin{array}{l}\text { Sex } \\
\text { Problems }\end{array}$ & $L O C$ & $\begin{array}{l}\text { Overall } \\
\text { Mean }\end{array}$ \\
\hline $\begin{array}{l}\text { Whiplash } \\
\text { Head } \\
\text { Overall Mean }\end{array}$ & $\begin{array}{l}46(3.6) \\
36(3 \cdot 6) \\
41 \cdot 0\end{array}$ & $\begin{array}{l}51(4 \cdot 7) \\
49(3 \cdot 9) \\
50 \cdot 0\end{array}$ & $\begin{array}{l}67(2 \cdot 3) \\
58(3 \cdot 6) \\
62 \cdot 5\end{array}$ & $\begin{array}{l}46(5 \cdot 7) \\
34(6 \cdot 1) \\
40 \cdot 0\end{array}$ & $\begin{array}{l}59(4 \cdot 3) \\
57(3 \cdot 1) \\
58 \cdot 0\end{array}$ & $\begin{array}{l}57(2 \cdot 6) \\
51(3 \cdot 1) \\
54 \cdot 0\end{array}$ & $\begin{array}{l}54 \cdot 3 \\
47 \cdot 5 \\
50 \cdot 9\end{array}$ \\
\hline
\end{tabular}


subjects for the likelihood judgement group; mean speeds for the speed rating group) and Spearman Rank Order correlations were calculated. The rank order correlation between likelihood judgements for the LOC and no LOC descriptions was very high $(r=0.93, p<0.001)$. This high correlation in combination with the overall higher mean ratings for the LOC condition indicates that the common belief is that LOC with whiplash injuries exacerbates the symptom complex but does not change it qualitatively.

The rank order correlation for the speed ratings of symptoms for whiplash and head injury was 0.90 , $p<0.001$. This high correlation suggests that people believe that whiplash and head injuries result in a similar pattern of symptoms. However, the overall comparison of mean ratings showed that higher speeds were considered necessary to produce the symptoms with whiplash injuries.

Finally, the generality of the judgements can be estimated by comparing the data from the likelihood judgement and the speed rating groups. To the extent that it is reasonable to assume that common symptoms should be more likely to occur with lower velocity impacts, then the rank ordered judgements of the two groups should be highly and negatively correlated. The correlation was $-0.65, p<0.001$, indicating that the two types of judgements (likelihood and requisite speed), each made by a different group of raters, identified a similar symptom complex.

\section{Discussion}

The results bear on at least two important issues related to the post-traumatic syndrome. The first issue concerns knowledge about the psychological sequelae following trauma. Although over $80 \%$ of the participants thought that the common physical symptoms were a likely outcome, less than $50 \%$ believed that the cognitive symptoms were likely. Moreover, the speeds thought to be necessary to cause cognitive symptoms were as extreme as those thought requisite for the distractor symptoms that are rarely or never reported. Cognitive dysfunctions are, however, commonly reported. These findings suggest that lay people may show little understanding or sympathy for memory problems, loss of concentration, and similar cognitive symptoms. Secondly, the findings suggest also that these symptoms are unlikely to be simulated by malingerers if they are basing their simulations on common knowledge.

These results contrast with those reported by trauma victims. Barnat ${ }^{5}$ reported the symptoms of post-traumatic headache patients who had experienced mild to moderate closed head and neck injuries. After an average of $\mathbf{4 0}$ months post-injury, $\mathbf{5 7 \%}$ of his sample reported having continued memory problems.
In addition, several specific kinds of memory difficulties were reported by many of the patients in his sample.

Most of the people in our study did not believe that head injury victims ever experience the symptoms reported by Barnat. Nor did they believe that someone who has suffered a whiplash injury is likely to experience difficulty with social relationships or financial problems as a result of the injury. However, the head trauma patients that we have tested in our research frequently complained that they experienced difficulties with emotional control, anxiety, and depression that had a profound effect on their social relationships. Owing to memory and concentration problems, as well as physical pain, their ability to work is severely curtailed and financial difficulties often result. It is possible that the people who participated in the present research considered most of the symptoms associated with such injuries to be of such short duration that the victim's personal relationships and, thus, finances were unlikely to be strained.

The participants' judgements of the relationship between speed at impact and the resulting injury were interesting. When the driver of a stationary car received a direct blow to the head following a rear-end collision, the speed of the offending vehicle judged to be necessary to cause brain damage approached $60 \mathrm{~km} / \mathrm{h}$. Even common physical symptoms (pinched nerve in the neck, headache, dizziness, neck pain, etc.) were thought to require speeds of $34 \mathrm{~km} / \mathrm{h}$ when a direct blow to the head resulted from the accident. Even higher speeds were judged to be necessary when a whiplash injury occurred. These beliefs are not in accord with what is known from research. Research using anthropomorphic dummies has demonstrated that at speeds of less than $24 \mathrm{~km} / \mathrm{h}$, the head accelerates at 10 times the force of gravity. ${ }^{6}$ Diffuse axonal degeneration, particularly in the brainstem ${ }^{7}$ and contusions on cortical surfaces ${ }^{8-10}$ have been reported following the experimental induction of a rotational acceleration injury to monkeys over a broad range of $g$ forces.

Although laypeople have a limited understanding of some aspects of the PTS, they do have more accurate knowledge about other types of symptoms. The commonly reported physical symptoms were judged to be the most likely and to occur at the lowest speeds of impact. Less commonly reported physical symptoms were thought to be less likely and to require higher speeds of impact. Consistent with this knowledge, the distractor items were the physical symptoms judged to be least likely and to require the highest speeds. Loss of consciousness was believed to enhance the likelihood of the symptoms and lower speeds of impact were judged to be necessary to produce the symptoms when the head struck the 
windshield as compared to a whiplash injury.

Nevertheless, the data indicate that the participants have a limited knowledge of the extensive range of symptoms that may occur following a minor head injury, and are particularly unaware of the cognitive deficits that may occur. We should note that our sample was drawn from a population of over 2000 introductory level psychology students. Because the majority are in their first year of university from the Faculties of Arts and Science, they are unlikely to have any medical or specialist knowledge of any kind. Although caution must be exercised, to the extent that judgements of our sample can be generalised to the remainder of the lay population, there are two notable implications of the findings. First, it seems unlikely that patients with persistent complaints (especially regarding cognitive dysfunctions) derive their symptoms from common knowledge about minor head or whiplash injuries. Second, laypersons, such as jury members, judges, lawyers, friends, family members, and social workers may be sympathetic to physical complaints expressed by the accident victim but they may be less tolerant or accepting of cognitive, sexual, or consequent social problems. A description of the relation between accident conditions and symptoms, as well as the nature of the symptoms may facilitate understanding of the victim's situation.

This research was partially funded by a grant from the Alberta Occupational Health and Safety Heritage Grant Program. Thanks are extended to Dr W Vanast for his comments on the stimulus materials.
References

1 Binder LM. Persisting symptoms after mild head injury: A review of the postconcussive syndrome. J Clin Exp Neuropsychol 1986;8:323-46.

2 Guthkelch AN. Posttraumatic amnesia: Post-concussional symptoms and accident neurosis. Eur Neurol 1980;19:91-102.

3 Hodge JR. The whiplash neurosis. Psychosomatics 1971;12:245-9.

4 Miller H. Accident neurosis. Br Med J 1961;i:919-25, 992-8.

5 Barnat MR. Post-traumatic headache patients I: Demographics, injuries, headache and health status. Headache 1986;26:271-7.

6 Severy DM, Mathewson JH, Bechtol CO. Controlled automobile rear-end collisions, an investigation of related engineering and medical phenomena. Canadian Services Medical Journal 1955;11:727-59.

7 Jane JA, Steward O, Gennarelli TA. Axonal degeneration induced by experimental noninvasive minor head injury. J Neurosurg 1985;62:96-100.

8 Gennarelli TA, Segawa H, Wald U, Czernicki A, Marsh $\mathrm{K}$, Thompson C. Physiological response to angular acceleration of the head. In Grossman RG, Gildenberg PL, eds. Head Injury: Basic and Clinical Aspects, New York: Raven, 1982:129-40.

9 Adams JH, Graham DI, Gennarelli TA. Neuropathology of acceleration-induced head injury in the subhumano primate. In: Grossman RG, Gildenberg PL, eds. Head Injury: Basic and Clinical Aspects, New York: Raven, 1982:141-50.

10 Ommaya AK, Faas F, Yarnell P. Whiplash injury andō brain damage. JAMA 1968;204:285-9. 